\title{
Implications of ERP as Service
}

\author{
Gustaf Juell-Skielse ${ }^{1}$ and Håkan Enquist ${ }^{2}$ \\ ${ }^{1}$ Stockholm University \\ gjs@dsv.su.se \\ ${ }^{2}$ School of Business, Economics and Law, University of Gothenburg \\ hakan.enquist@handels.gu.se
}

\begin{abstract}
In this paper we present implications for using and delivering Enterprise Resource Planning as services (ERP-as-a-service). The objective is to construct a framework of opportunities and challenges for users and suppliers of ERP-as-a-service. The framework is based on a combination of literature study and field study and includes approximately 80 implications. New implications, not found in literature, were identified in the field study. Examples of new implications include: more focus on IT-value; simplified phasing of implementation and improved supplier brand. For future research it is suggested that the framework is tested in a larger setting and that implications are prioritized for certain industries and types of business models.
\end{abstract}

Keywords: ERP-as-a-service, Implication, Software-as-a-service, Enterprise resource planning, Service orientation, Cloud computing.

\section{Introduction}

Recently, service orientation has emerged as an important change driver in private and public sector organizations. Service orientation offers means to radically improve customer service, business processes and sourcing of information systems. Suppliers begin to offer information systems according to service based business models, such as Software as a Service and Cloud Computing, rather than standard application packages. Service based business models challenge conventional payment models, on-premise installations and monolithic designs of standard application packages and have vast implications for both users and suppliers of information systems. Through service based business models, suppliers can expand their potential customer base and offer more choices that enable customers to focus on core competencies and reduce initial investments in standard applications [1].

So far, research in service oriented software has concentrated on user and supplier implications on limited application areas such as Customer Relationship Management [2]. However, a great challenge for service oriented software is the migration of Enterprise Resource Planning (ERP) from locally installed systems to ERP-as-aService. ERP systems are complex standard application packages that include a large variety of application areas and are configurable to satisfy needs from many users 
with high demands on integration with legacy systems. Due to its profound impact on user organizations, ERP is challenging to implement [3]. There are numerous examples of companies that have suffered severely from poorly conducted ERP implementations where the bankruptcy of Foxmeyer Drug in 1996 [4] represents an early example.

ERP represents a significant portion of the global software industry and suppliers are beginning to offer ERP-as-a-service. In 2008 the size of the ERP market corresponded to 34.4 billion USD in software licenses and 103 billion USD in ERP related services [5]. New suppliers, such as Netsuite and 24Sevenoffice, appear on the ERP market offering service based ERP alongside with established suppliers, such as Lawson. Lawson has migrated its Enterprise Management System to a service and use the Amazon Elastic Computer Cloud infrastructure for service delivery [6].

ERP is a large, complex and business critical investment and it is necessary to understand the organizational impact of ERP-as-a-service to make rational investment decisions. ERP-as-a-service represents a major shift in what is delivered, how and by whom. For example, ERP-as-a-service has the potential to decrease up-front investments and reduce implementation costs and risks for ERP [7, 8, 9]. But it could also reduce the possibilities to configure and integrate the software to specific user needs [10]. Furthermore, ERP-as-a-service can serve as an interesting case for service orientation. The conventional ERP business model is product centric and revolves around the ERP system which is implemented on the premises of the using organization, while ERP-as-a-service follows a service dominant logic [11] where users consume services bundled as offerings delivered over the Internet by a supply chain of service providers.

In this paper we investigate implications for organizations that use Enterprise Resource Planning as a service (ERP-as-a-service) rather than the conventional ERP business model. The objective is to establish a framework of implications for ERP-asa-service. The framework includes opportunities and challenges for users and suppliers of ERP-as-a-service. It is constructed using a combination of literature study and a cross-sectional field study involving user and supplier organizations. This paper provides a case of service orientation for a large portion of the software industry and a framework for implications of ERP-as-a-service. By implications we mean opportunities and challenges for users and suppliers of ERP-as-a-service. The framework includes implications not earlier identified in literature as well as additional evidence for implications found in literature. Several field studies of ERPas-a-service are used to collect data, including small and large public sector and private sector organizations, users as well as native and migrant ERP-as-a-service suppliers. The framework provides practice with a basis for evaluating sourcing alternatives to conventional ERP and as a guide to risk management when implementing ERP-as-a-service.

The article is organized as follows. In the next chapter implications are defined followed by a discussion on the characteristics of ERP-as-a-service. In chapter four the methodology is presented, including a presentation of the field study participants 
and a methodological discussion. In chapter five, the framework is presented followed by a discussion in chapter six. In the final chapter, conclusions are made together with suggestions for future research. A complete framework with references to literature and field study cases is found in the appendix.

\section{Implications}

In this paper, we use implication, when we refer to effects that are consequences of adopting ERP-as-a-service. Authors use different terms when discussing implications. For example [1] use the terms benefit and risk while [12] uses the terms opportunity and challenge. Authors also use terms like advantage [8], disadvantage [9] and uncertainty [13].

In this paper we follow Cusumano [12] and specify implication in terms of opportunity and challenge. By opportunities we mean implications that may have positive effects on the effectiveness of the ERP-as-a-service user or the ERP-as-aservice supplier. An example of an opportunity is reduced operating costs. By challenges we mean implications that may have negative effects on the effectiveness of the service user or the service supplier. An example of challenge is increased demands for technical skills.

\section{Enterprise Resource Planning}

Enterprise Resource Planning (ERP) represents a significant market for suppliers and consultants providing ERP related services to using organizations. In 2008 the size of the ERP market corresponded to 34.4 billion USD in software licences and 103 billion USD in ERP related services [5]. ERP systems are standard application packages designed to meet demands from different users [14]. ERP systems are enterprise wide and include administrative functions for finance, human resources, production, logistics and sales and marketing. The various components or modules are integrated across an enterprise through a central database [3]. ERP provides support to coordinate the work along business processes and to monitor activities spanning large organizational and geographical distance [15]. ERP-systems also provide embedded knowledge, often referred to as best practices [16], that supports using organizations to enhance their business processes $[16,17]$ within the company and between the company and its partners [17]. ERP has been extended to include more advanced planning functions such as supply chain management and customer relationship management and improved support for e-business [17].

ERP systems are standard applications and represent economies of scale in development since development costs can be shared among several customers $[18,19$, 20]. Standard applications aggregate knowledge and experiences from earlier development and represent fewer risks compared to software developed in-house. However, ERP implementations are associated with several risks for user organizations [21]. For example, there is a risk that a company's organizational strategy, structure and processes are not aligned with the chosen ERP system. In order 
to increase alignment it is often suggested that organizations adjust their operational processes to fit the processes embedded in the software. Another risk is that ERP projects escalate and lack control which is caused by decentralized decision making and subsequent ineffective ratification of decisions.

The conventional business model of ERP involves three actors: using organization, ERP vendor and consultant [22, 23]. In brief, the using organization selects and implements packaged software from an ERP vendor. The vendor has designed the software taking into account current best practices for processes and business domains. The vendor upgrades the software in new releases regularly. ERP vendors partner with consulting firms that help using organizations to select, implement and use the ERP software. Partnerships with the major ERP vendors are usually offered based on a certification procedure. The revenue model for ERP vendors is based on the number of licenses needed by the using organization. Services provided by consulting firms are essentially paid for on a resource basis, i.e. per hour. Interaction between user organizations, consultants and ERP suppliers vary between phases of the ERP lifecycle. From a using organization's perspective, the ERP lifecycle consists of several phases: analysis, selection, set-up, deployment, operation, improvement and settlement $[24,25,26]$. Consultants are normally more involved in the earlier phases of the ERP life cycle, while ERP vendors become more actively involved from the set-up phase and onwards.

\subsection{ERP-as-a-Service}

ERP-as-a-service is ERP delivered through a SaaS model [27]. SaaS (Software-as-aService) is a business model where customers access business functionality remotely, usually over the internet [28]. The main characteristics that distinguish ERP-as-a-service from other types of SaaS models are related to the content of the service. In ERP-as-aservice, the service includes elementary offerings for enterprise-wide, integrated and standardized business functions and support for business processes which are characteristic to ERP. Essentially it is an ERP application delivered as a service [29] accessed through a web browser [30]. In addition to business functionality, the technical infrastructure, the right to use the service, hosting, maintenance and support services are bundled into a single service [28]. The ownership of the software is separated from its use $[28,31]$. However, the possibilities to customize the service are limited due to the multi-tenant infrastructure [32, 33].

Users of ERP-as-a-service include most types of companies, regardless of size or industry [2]. The primary channel is the internet [28]. However, there are concerns regarding the organizational size. Gartner Group claims that ERP as-a-service is only a viable business model for small and medium sized organizations [34] while Benlian et al. [35] found no correlation between size and benefits. Due to the scalability of services, organizations can make limited deployments to test reliability and then scale up their solutions [36]. 
The infrastructure of ERP-as-a-service consists of service providers that remotely operates and maintains the software on their own hardware or hardware provided by third-parties [8]. Service providers use a one-to-many distribution model where the infrastructure most often has been prepared for multi-tenancy [37]. The application is delivered from one instance with a single source code and configurable metadata for each tenant have several advantages [38]. There could also be several service providers co-operating to deliver a joint service consisting of several smaller services. The interface to the customer could be managed by an intermediary who coordinates supply chains of service providers [39] or the customer may combine several services into a coherent service on his own. The development of the software is continuous and delivered to the customer through incremental updates [8] and version free software [1]. The solution is modularized according to SOA principles [40].

The financial aspects of the ERP-as-a-service business model include usage based payment models $[28,1]$ and cost models that are unconnected to the investment costs for developing the software [1].

\section{$4 \quad$ Method}

A cross-sectional field study [41, 42] was performed in order to gather information about implications. 17 firms are included in the sample which includes eight pairs of users and suppliers of ERP-as-a-service and one additional supplier where the user organization was undefined, see table 1. By pairs of users and suppliers we mean that they represent the consumer side and provider side of the same ERP service. Sample organizations were selected based on the following criteria:

- Service content should be similar to the functionality of a conventional ERP system. The object of study is ERP-as-a-service and not merely Software-as-aservice since ERP is a type of software with specific characteristics, see section "Enterprise Resource Planning", above.

- User organizations of different size since smaller organizations are thought to adopt ERP-as-a-service more easily than large organizations [34].

- User organizations from different industries since ERP adoption vary between industries [43].

- Supplier organizations with different backgrounds: suppliers new to the ERP market (native); established ERP suppliers (migrant) and established consulting firms which offer ERP-as-a-service complementary to consulting services (also migrant).

Data has been collected using an open form without confronting participants with implications found in literature. The participants have been directed to focus on the business models of the case companies before and after using ERP-as-a-service and the implications of these changes. Hereby it is believed that participants have been 
less biased when reporting implications than if they would have had to respond to a number of statements about implications. The form was tested on two pilot organizations and discussed with a reference group of ERP-as-a-service suppliers, consultants and organizations using ERP-as-a-service. The cases were selected in cooperation with the members of the reference group and are either implemented business models or business model designs for service oriented ERP. The field studies were documented during 2009-2011. Field study write ups were provided by key personnel with support from the authors of this paper. Key personnel included managers at ERP suppliers, project managers at consultants and managers from using organizations. The authors provided support in the form of written guidelines for the use of the form, individual and group meetings to discuss cases and in some situations also documentation support.

Table 1. Field study organizations

\begin{tabular}{|c|l|l|l|l|}
\hline $\begin{array}{l}\text { Field } \\
\text { Study }\end{array}$ & User & $\begin{array}{l}\text { Size of } \\
\text { Customer } \\
\text { Organization }\end{array}$ & Supplier & Case Provider \\
\hline A & $\begin{array}{l}\text { Real estate } \\
\text { management firm }\end{array}$ & Small & Hogia & Hogia \\
\hline B & Travel agency & $\begin{array}{l}\text { Small to } \\
\text { medium }\end{array}$ & Scandisys & Microsoft \\
\hline C & $\begin{array}{l}\text { Manufacturing } \\
\text { company }\end{array}$ & Medium & Systeam & Systeam \\
\hline D & Service company & Medium & Agresso & Agresso \\
\hline E & Local business unit & Large & Stena Metall IT & Stena Metall AB \\
\hline F & $\begin{array}{l}\text { Manufacturing } \\
\text { company }\end{array}$ & Small & 24SevenOffice & 24SevenOffice \\
\hline G & Accounting firm & Small & Acando & Acando \\
\hline H & Media company & Medium & Netsuite & Alterview \\
\hline I & N/A & $\begin{array}{l}\text { Medium to } \\
\text { large }\end{array}$ & Lawson & Lawson \\
\hline
\end{tabular}

A structured literature review was performed in parallel with the field study. The search process was a digitally aided search for journal articles, conference proceedings and white papers since 2000. The main concepts used in the search process were enterprise resource planning, service orientation and implication. The aim of the search process was to identify work that discusses the implications of service orientation on enterprise resource planning. Several keywords for the three concepts were included in the search:

- Enterprise resource planning, ERP

- Service Orientation, ERP-as-a-service, Software as a service, SaaS, Cloud computing, Application Service Provider

- Implication, benefit, advantage, opportunity, risk, challenge, disadvantage, uncertainty 
The initial search resulted in approximately 800 identified articles. These articles were reviewed by the authors and articles that discussed implications for users or suppliers were included in the literature review. A total of 32 articles were selected.

Statements regarding implications were collected from the field study write-ups. To relate the results to previous research, statements were interpreted, and mapped onto implications found in literature. Some implications found in the field studies map well onto implications found in literature while other implications are only found in the field studies, see appendix.

\section{Framework of ERP-as-a-Service Implications}

In this section, a framework of implications is presented from the perspective of the user and the perspective of the supplier. The framework is created from the results of the literature study and the results of the field study. The implications are divided into opportunities and challenges. New implications not found in literature are marked with an asterisk (*) and further described below, see section "New Implications". The implications with references to literature and field studies are found in appendix.

\subsection{User Perspective}

The user opportunities with ERP-as-a-service are primarily related to financial advantages infrastructural changes, see table 3 . The financial opportunities come from reduced investment and implementation costs as well as productivity improvements and reductions in stock and personnel. Infrastructure opportunities lie in improved business processes and in sourcing software and IT infrastructure as services from third parties. In addition there are opportunities to improve customer responsiveness and to focus more on core processes.

The user challenges of ERP-as-a-service are primarily related to infrastructural and organizational changes, see table 2. The infrastructure challenges concern the implementation project and the dependency on third parties for service delivery. The organizational challenges relate to changes in organizational responsibility between users and suppliers where suppliers take over responsibility from users' IT departments. 
Table 2. User implications

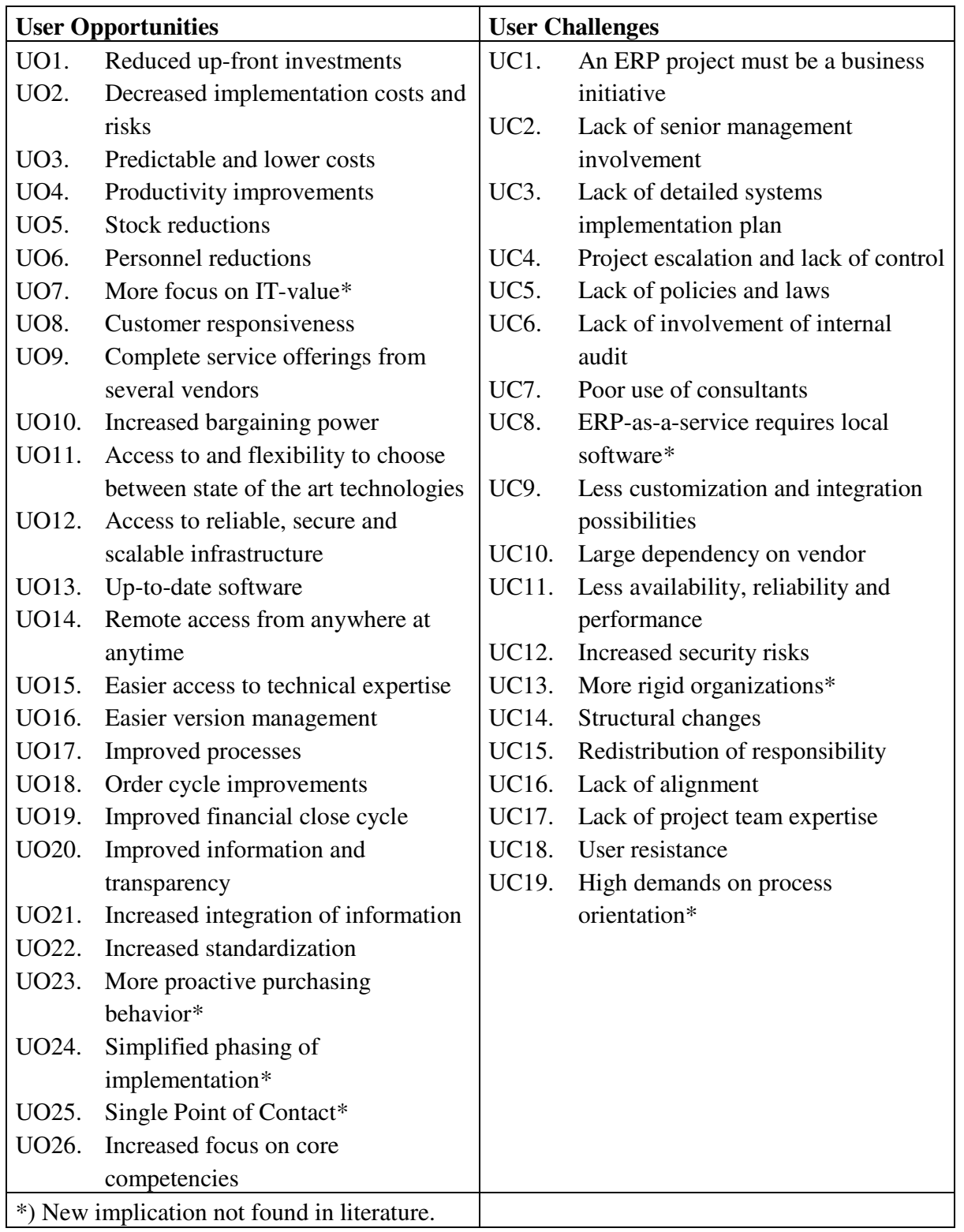

\subsection{Supplier Perspective}

Supplier opportunities are related financial advantages, but also to the possibilities to expand the customer base and to build new skills, see table 3 . The financial opportunities come from more predictable revenue flows at a potentially greater 
profit. From a customer perspective there are opportunities to expand the customer base and to offer more choices to customers. There are also opportunities to build economies of scale in distribution and operation as well as leverage domain knowledge and build application expertise.

Supplier challenges are related to finance but also to service development and organizational changes, see table 3 . Financial challenges come from high initial investments and turnover reductions when migrating to services. From a service development perspective there are challenges related to serviticizing software products and to changes in contractual agreements. Infrastructure wise there are great challenges in developing multi-tenant effective applications and to manage networks of suppliers. From a learning and growth perspective, the challenge is to establish new sales processes and sales competence.

Table 3. Supplier implications

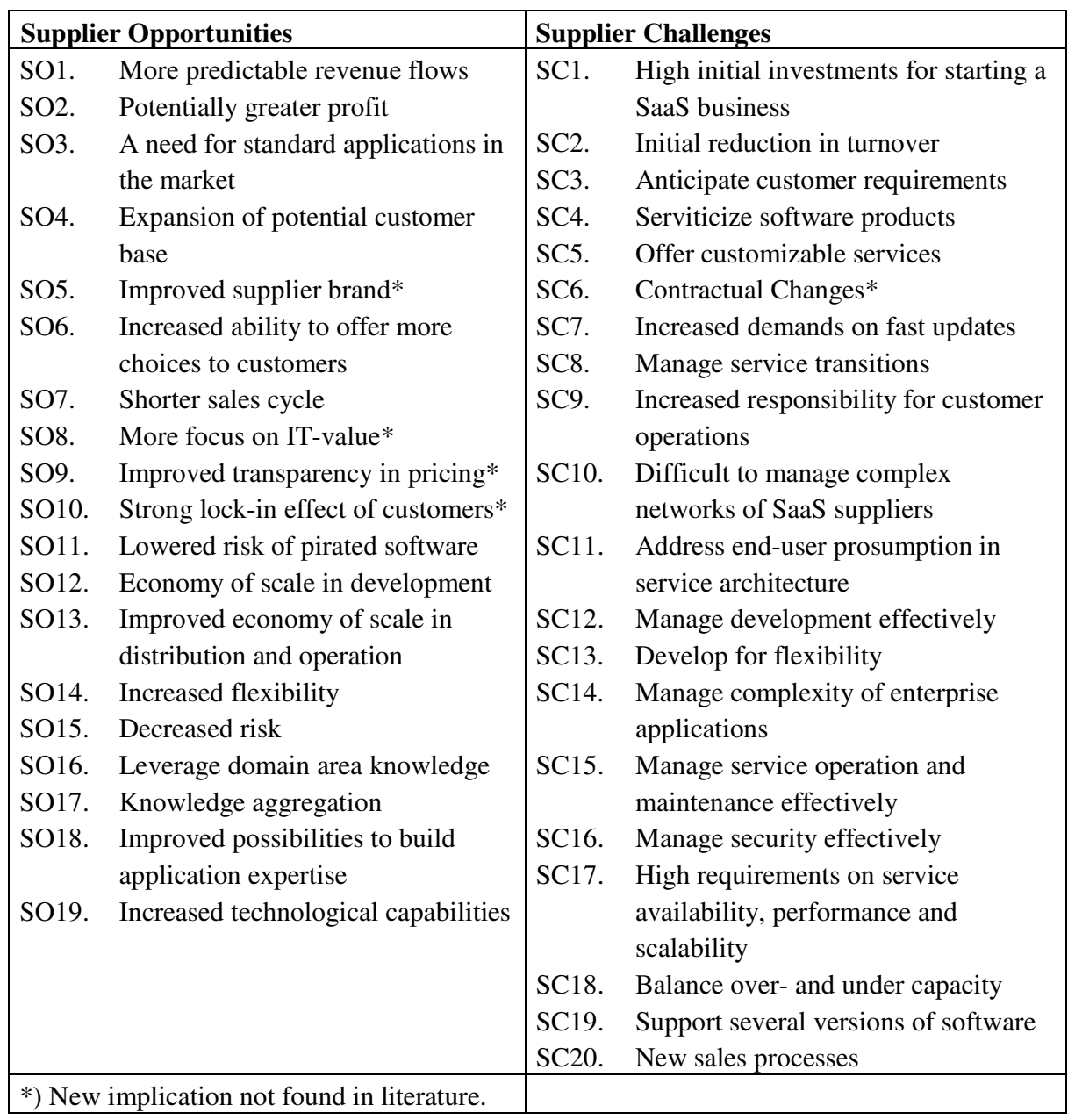




\subsection{New Implications}

The field studies revealed some new implications not found in literature, see table 4 . New implications are identified for both users and suppliers.

Table 4. Summary of new implications

\begin{tabular}{|l|l|}
\hline User & Supplier \\
\hline Opportunities & Opportunities \\
UO7. More focus on IT-value & SO5. Improved supplier brand \\
UO23. More proactive purchasing behavior & SO8. More focus on IT-value \\
UO24. Simplified phasing of implementation & SO9. Improved transparency in pricing \\
UO25. Single point of contact & SO10. Strong lock-in effect of customers \\
Challenges & Challenges \\
UC8. ERP-as-a-service requires local & SC6. Contractual Changes \\
UC13. More rigid organizations & SC8. Manage service transitions \\
UC19. High demands on process orientation & SC9. Increased responsibility for \\
& SC20. New sales processes \\
\hline
\end{tabular}

\subsection{More Focus on IT-Value (UO7 and SO8)}

ERP-as-a-service improves users' focus on IT-value since it becomes easier to define costs related to specific service functions or service modules. Customers can get a better picture of the total cost for the value created by the service. There are no hidden costs. Customers understand better what drives costs and can more easily identify where to make improvements.

SaaS refines the roles and you get a clear model of cooperation. It becomes easier to justify integrated value creation involving both users and suppliers. The relationship between business needs and delivery of service becomes clearer and there is a shift from charging consulting hours to improving organizational performance. (Case CSysteam)

\subsection{More Proactive Purchasing Behavior (UO23)}

ERP-as-a-service can affect the working relationship between users and consultants. One of the suppliers notes that their customers become more proactive in how they purchase consulting services, from a needs-based purchasing behavior to a standing order with a fixed amount of hours per week.

There is a shift in how customers buy consulting hours, from reactive purchasing behavior to proactive. An example is when customers purchase a certain number of hours per week instead of purchasing hours when there is a problem. (Case C Systeam) 


\subsection{Simplified Phasing of Implementation (UO24)}

Historically, most companies have preferred Big-Bang strategies when implementing ERP [44] in order to shorten implementation time and cost for consultants. Service based enterprise systems make it easier for users to phase implementations.

It is easy for the customer to add new functionality, for example start with finance and then continue with supply chain management. (Case G-Acando)

\subsection{Single Point of Contact (UO25)}

With ERP-as-a-service it becomes clearer for users how to get support. Support organizations for conventional ERP tend to have several lines of support and different contact persons for different types of problems.

[Customers have] one support organization to turn to whether the problem is related to systems usage, program error or operational issues. (Case D - Agresso)

\subsection{ERP-as-a-Service Requires Local Software (UC8)}

In order to be able to use enterprise software services organizations may have to install additional software locally. This is software, such as integration engines or software for user administration, which is required by the service to function properly. Additional software may come as a surprise to the using organization and be considered a hidden cost if the user is not informed in advance.

User administration and single sign-on need a new technical solution when buying ERP-as-a-service. (Case D-Agresso)

\subsection{More Rigid Organizations (UC13)}

There is a risk that organizations that orient their IT towards services, such as ERP-asa-service, become more rigid since they attract a different type of employees. Service oriented organizations tend to be more structured and less agile.

We see a risk that individuals and organizations change to become more structured and less agile. This is both positive and negative. Other types of individuals are attracted ... (Case C-Systeam)

\subsection{High Demands on Process Orientation (UC19)}

Suppliers experience a difficulty in selling service oriented ERP to customers that are not process oriented, for example organizations that apply an application centric maintenance model find it hard to adopt a service oriented delivery model. 
The [user] organizations are not process oriented; it is difficult to be service oriented if you are not process oriented. This is a challenge for the customer. (Case C Systeam)

\subsection{Improved Supplier Brand (SO5)}

Suppliers brand image can be improved since they take full responsibility for the delivery of the enterprise system. Suppliers invest more in technical expertise and will no longer be affected by poorly installed and operated software at their customers' sites. Often, suppliers can be blamed for delivering a poor system when customers lack the technical proficiency to install and operate the software well.

Hogia can take responsibility for the entire deployment; there will be no problems related to that customers' technology do not function properly. Today it is complex to operate [ERP] solutions which many times have a negative effect on Hogia's [conventional ERP] solution. (Case A - Hogia)

\subsection{Improved Transparency in Pricing (SO9)}

ERP-as-a-service can improve transparency in pricing since costs for infrastructure, operation and maintenance are included in the service price. There are no or minor additional costs for using the service. From a user perspective it becomes clearer what the total price for ERP is and how much extra costs additional services, such as separate modules, incur.

Business units understand better and accept easier the basis for charging costs. Before, costs were often questioned when business units did not understand what caused them. This led to that some business units required to buy IT-services from third parties, which decreased the possibilities to coordinate and share IT resources among business units. (Case E - Stena Metall)

\subsection{Strong Lock-in Effect of Customers (SO10)}

A great advantage of service orientation is the possibility of changing from one service supplier to another. However, this may not be the case for ERP-as-a-service since ERP is a complex type of application. ERP suppliers still believe that customers will stay long once they have started to use an ERP service due to the complexity of changing from one ERP service to another ERP service.

Customers stay around 7-10 years due to satisfaction with services and complexity in changing services. This means that we dare to offer services without long terms. (Case C-Systeam)

\subsection{Contractual Changes (SC6)}

Suppliers that migrate from conventional ERP to ERP-as-a-service there is a need to re-define service delivery which affects how contracts are written. 
We have to re-define fulfillment of delivery, when have you done what you promised in the sales process? (Case C-Systeam)

\subsection{Manage Service Transitions (SC8)}

In conventional ERP, ERP systems are often operated side by side with legacy systems during long transition periods. Suppliers of ERP-as-a-service anticipate the same situation when customers decide to change from one ERP service supplier to another. There are few models and little experience available for this type of transition. Today, some suppliers of ERP-as-a-service offer migration functions to make it easier for customers to migrate data to new services.

... there is a lot of export possibilities to export data so if you like to stop the subscription, you can do it yourself by pressing a button. (Case H-Alterview)

\subsection{Increased Responsibility for Customer Operations (SC9)}

Service orientation makes ERP more of a utility which requires that suppliers take greater responsibility for their customers' businesses. Suppliers cannot just switch off utility services even if customers neglect to pay for them, it would hurt customers' operations too much.

Although there is a three months mutual termination of contract, we cannot [just] terminate the contract. If we terminate the contract it will cause too much harm to our customers' businesses. (Case C-Systeam)

\subsection{New Sales Processes (SC20)}

Suppliers migrating from offering conventional ERP to offering ERP-as-a-service need to establish new sales processes. Sales cycles become shorter and sales remuneration change from being based on license sales to being based on usage, subscription and time period. Sales personnel can also bypass conventional purchasing routines and start to sell to end-users.

[ERP-as-a-service] represents a great shift for a company where the entire remuneration system is based on license sales per sales person. Today you don't get a raise based on customer value created. The whole [remuneration] system must be redesigned in order to enable ... sales bonus based on service agreements, for example by calculating the net present value of the sales price over a five year period. (Case $C$ - Systeam)

\section{Discussion}

In the discussion we highlight some aspects of the framework for implications of ERP-as-a-service. We will elaborate on some of the more interesting new 
implications and discuss some contradictions found in the framework. We will also discuss the relevance of implications for companies migrating from conventional ERP to ERP-as-a-service. In addition, the service orientation of the ERP market will be discussed followed by a methodological discussion.

\subsection{More Focus on IT Value}

An interesting finding among the new implications is the increased focus on IT value, both from the user perspective (UO7) and from the supplier perspective (SO8). ERPas-a-service makes it easier to link business opportunities enabled by ERP and the costs for these opportunities. Also, ERP-as-a-service makes it easier for companies to focus on their core competences and not spend time and resources on building inhouse application competence required for conventional ERP. This should mean that the sales process for ERP-as-a-service will become different from the sales process for conventional ERP. As a consequence sales personnel needs to build a better understanding of how ERP services contribute to improved IT value in different industry domains. Hence, sales roles become more consultative.

\subsection{Simplified Phasing of Implementation}

Simplified phasing of implementation (UO24) refers to the complex and long implementation processes of ERP spanning several years (Sumner 2005). Service orientation seems to simplify this for two reasons. First it becomes easier to add new functionality which means that the using organization can start with a core of functionality and then easily add new functionality over time. The second reason is that the roll-out of the solution to different business units becomes simpler when you do not need to install and maintain the system locally.

\subsection{Lock-in of Customers}

Another interesting result is the lock-in of customers. A great advantage of service orientation is the increased possibility to change service supplier. But this seems not to be the case for ERP-as-a-service. Suppliers of ERP-as-a-service believe that customers will stay long once they have started to use an ERP service due to the difficulty of changing from one ERP service to another ERP service. ERP is a complex type of information system and the process- and structural adjustments made by an organization to effectively adopt and use ERP appear to still make it difficult for a company to quickly change from one ERP service to another. This hampers the user opportunities related to increased bargaining power and increased flexibility (UO10, UO11).

\subsection{Improved Supplier Brand}

ERP-as-a-service appear to be a viable strategy for suppliers who suffer from poor onpremise installations. Their brand image (SO5) can be improved since they can take full responsibility for the delivery of the enterprise system. Hereby they will no longer 
be blamed for delivering a poor system when customers lack the technical proficiency to install and operate the software well on their own premises. ERP-as-a-service extends suppliers' control over their products when they are made available to the customer's own value creating activities, the so called representative knowledge process [45].

\subsection{More Rigid Organizations}

A surprising result is that service orientation may lead to using organizations become more rigid (UC13). The argumentation is that organizations that source IT as services tend to attract different types of employees with a more administrative profile than organizations that invest more in in-house development. This finding challenges what we have learned so far about how service oriented software enables organizational flexibility (UO11).

\subsection{More or Less Secure Solutions}

One of the more interesting discussion illustrated by the framework is the question of whether ERP-as-a-service is a more secure IT solution than on-premise installations of ERP systems or a less secure solution. ERP-as-a-service can offer access to a reliable, secure and scalable infrastructure (UO12) due to the specialized IT-skills developed by the provider. But ERP-as-a-service could also increase the risk of lowered reliability and performance since vendors deliver services over the Internet and share application and server capacity (UC11). Moreover, ERP-as-a-service increases the security risk of losing data to third party since vendors share application and server capacity (UC12).

For a small or medium sized company the supplier of an ERP service may provide a better infrastructure than the company itself may be able to do while a large company may have both higher security requirements and internal capabilities to operate a more secure and reliable infrastructure. Several suppliers included in the field study claim that they are able to offer a better infrastructure to than their customers are able to establish on their own. The suppliers have also found that the question about security is moving from being a drawback to becoming a strength when selling ERP-as-a-service. Although one can claim that Internet delivery increases vulnerability of company data, one can also claim that most companies, even though they are operating their own infrastructure, open up their infrastructure to the Internet.

\subsection{Previous Use of ERP}

The framework of implications is based on literature on both SaaS implications and ERP implications, as discussed above in the Methodology section. As a consequence, the framework includes opportunities and challenges for companies new to ERP as well as companies new to service oriented ERP. For example, ERP enables companies to increase customer responsiveness through the use of ERP (UO8). This opportunity should be equally relevant to companies that begin to use ERP through a 
service and to companies that use conventional ERP. However, companies that migrate from conventional ERP to ERP-as-a-service, this opportunity is no longer relevant. They have already benefitted from this implication when they started to use ERP, although they were using conventional ERP at the time.

Therefore, an important variable hidden in the framework is companies' previous use of ERP. Users could be new to ERP when they start to use ERP-as-a-service or they could be migrants from conventional ERP. For users new to ERP most of the implications in the framework are relevant while for users migrating from conventional ERP to ERP-as-a-service only parts of the framework are relevant. The same goes for suppliers, that could be new entrants to the ERP market by offering ERP-as-a-service or they could be established on the ERP market through conventional ERP packages which they replace or complement by ERP-as-a-service. For example, the implication initial reduction of turnover (SC2) is only relevant to migrant suppliers.

\subsection{Service Orientation of the ERP Market}

ERP-as-a-service is a case of transformation of the software industry. ERP is a significant portion of the software industry and represent complex applications which are of vital importance to most organizations today. ERP-as-a-service shows how a new business model, enabled by technological development, opens up for new entrants to the ERP market and creates opportunities for established suppliers to gain competitive advantage by offering new services according to new business logic.

Since ERP is complex and has a great impact on the using organization it puts a lot of pressure on suppliers. The framework shows that suppliers need to invest in developing multi-tenant effective solutions that offers the same or better configuration and integration features as conventional ERP systems. This is a major investment for suppliers when migrating conventional ERP systems to ERP-as-a-service. For example, Lawson migrates the M3 system to a service where they still have to maintain multiple instances of the solution and possibly several versions in parallel. Netsuite, who doesn't carry the ballast of an old ERP system, started out in the late 90's with a small standardized service which has grown into an ERP service that challenges both SAP and Oracle in many user organizations.

ERP-as-a-service may be an indication of that the ERP industry is taking a first step from a fluid phase to a transitional phase where the focus is on process innovation rather than product innovation [1, 46]. Suppliers of ERP-as-a-service challenge user organizations' internal processes for installing and operating ERP systems by offering more robust and secure processes as services. Also, this extends suppliers' control over their products at customers' sites. However, there are great restraining forces to the migration of conventional ERP to ERP-as-a-service in terms of the large installed base of conventional ERP systems that still needs to be maintained and the huge investments made by consultants in building ERP implementation competence. In addition, conventional sales processes and remuneration practices of sales staff also restrain both users and suppliers to adopt a service oriented business model for ERP. 


\subsection{Methodological Discussion}

Quality in qualitative research, such as field studies, depends on how data is collected and how the analysis of collected data is conducted. To judge the quality of research presented in this paper, the following criteria [47] are discussed: credibility, dependability, transferability and confirmability. Credibility refers to that the results of the inquiry is believable and understandable from the eyes of the particpants. Dependability means that the reseracher shows that the process of research is logical and clearly documented. Transferability to which degree results can be generalized and transferred to other contexts. Confirmability relates to how well the results can be confirmed by others.

\subsection{Credibility}

The framework of implications is developed using a combination of literature review and cross-sectional field study. The implications derived from literature are based on different types of investigations. A few of them have been tested using statistical methods while others have been observed in case studies and some have only been argued for. Therefore the empirical grounding of implications derived from literature is only partially trustworthy. Hence, the field study provides additional support for some of these implications.

In order to ensure credibility of the framework, separate meetings have been held with representatives from the organizations included in the field study to judge the credibility of the results. Since the statements collected from the participants in the field studies were translated into English and then mapped onto implications derived from literature it was important to verify the credibility of the implications. Some clarifications were made as well as a few changes to implications and descriptions.

\subsection{Transferability}

The field study includes organizations which use or supply ERP-as-a-service. The organizations cover both public and private organizations including native and migrant suppliers. Therefore, there is no reason to believe that the framework could not be applicable to other users or suppliers of ERP-as-a-service. However, there are some concerns regarding the localization and size of these organizations that may restrict the transferability of the framework. First, although some of the participants are global organizations and the services are distributed over the Internet, they are all active on the Scandinavian market. Hence, the transferability could be limited to Scandinavian market conditions. Second, although there are small, medium and large organizations represented in the field study, there is by international standards a focus on medium sized organizations. There are no multinational companies among the users. Therefore the contribution by the field study is somewhat limited to Scandinavian market conditions and small to medium sized organizations. 


\subsection{Dependability}

Data has been collected since the start of the research project in 2008. At that point in time, ERP-as-a-service was a fairly unknown phenomenon. Since then, the concept of Software-as-a-service has become more established and we have seen the advent of Cloud Computing. The knowledge about these concepts and their implications have grown in general and among field study participants due to the learning taking place as an effect of the investigation. In parallel, the technology has been developed to become more secure, stable and multi-tenant effective. This means that today some implications are less relevant and new implications appear. For example, today security is less of an issue than three years ago. Therefore we can hardly expect to get the same results from a similar study if we were to conduct one.

\subsection{Confirmability}

The method is described above, see section Methodology, and the authors are willing to share readers with documents showing how statements have been translated and mapped onto implications found in literature.

\section{Conclusion}

In this paper we have presented a general business model for ERP-as-a-service and a framework for its implications. The framework is based on a combination of literature study and field study. ERP-as-a-service is primarily viewed as a process innovation and indicates that the ERP industry is leaving the fluid phase and slowly moves into the transitional phase. The framework can be used to further investigate types of service oriented business models for ERP.

Users can benefit from the framework in their IT and business planning short-term and long-term. For example users can adopt new sourcing strategies for ERP and plan the transition from conventional ERP to ERP-as-a-service. The framework supports the development of investment analysis by providing potential benefits, costs and risks for moving from conventional ERP to ERP-as-a-service. It can also be used to formulate strategic objectives, operational targets and key performance indicators to measure the fulfillment of these objectives and targets.

The framework can be use by ERP suppliers to plan for new business relationships with current customers and also identify potential new customers. The framework also supports suppliers in identifying important challenges with service orientation in general and specifically ERP-as-a-service.

Future research is suggested to include prioritization of implications for certain industries and types of organizations. 


\section{References}

1. Sääksjärvi, M., Lassila, A., Nordström, H.: Evaluating the software as a service business model: From CPU time-sharing to online innovation sharing. In: Isaisas, P., Kommers, P., Mc-Pherson, M. (eds.) IADIS International Conference e-Society 2005, Qawra, Malta, June 27-30, pp. 177-186 (2005)

2. Dubey, A., Wagle, D.: Delivering Software as Services. The McKinsey Quarterly, Web Exclusive, 1-12 (May 2007)

3. Davenport, T.H.: Putting the enterprise into the enterprise system. Harvard Business Review, 121-131 (July-August 1998)

4. Scott, J.E.: The FoxMeyer Drugs' bankruptcy: was it a failure of ERP? In: 5th Americas Conference on Information Systems, Milwaukee, WI, August 13-15 (1999)

5. Jacobson, S., Shepherd, J., D’Aquilla, M., Carter, K.: The ERP Market Sizing Report 2007-2012. AMR Research (2008)

6. Thornton, J.: Lawson Announces Full-Function ERP on Amazon Web Services Infrastructure, Lawson (March 2010), http: / / www. lawson. com/about-lawson/ news-room/news-releases/english/2010/lawson-announces-fullfunction-erp-on-amazon-web-services-infrastructure (last accessed April 15, 2011)

7. Chong, F., Carraro, G.: Architecture Strategies for Catching the Long Tail. Microsoft Corporation (April 2006), http://msdn.microsoft.com/en-us/library/ aa479069. aspx (last accessed June 6, 2011)

8. Choudhary, V.: Comparison of software quality under perpetual licensing and software as a service. Journal of Management Information Systems 24(2), 141-165 (2007)

9. Fan, M., Kumar, S., Whinston, A.B.: Short-term and long-term competition between providers of shrink-wrap software and software as a service. European Journal of Operational Research 196(2), 661-671 (2009)

10. Fuller, S., McLaren, T.: Analyzing Enterprise Systems Delivery Modes for Small and Medium Enterprises. In: AMCIS 2010 Proceedings. Paper 380 (2010)

11. Vargo, S.L., Lusch, R.F.: Service-dominant logic: continuing the evolution. Journal of the Academy of Marketing Science 36(1), 1-10 (2008)

12. Cusumano, M.A.: The changing software business: Moving from products to services. Computer 41(1), 20-27 (2008)

13. Vassiliadis, B., Stefani, A., Tsaknakis, J., Tsakalidis, A.: From application service provision to service-oriented computing: a study of the IT outsourcing evolution. Telematics \& Informatics 23(4), 271-293 (2006)

14. Nilsson, A.G.: Using Standard Application Packages in Organisations - Critical Success Factors. In: Nilsson, A.G., Pettersson, J.S. (eds.) On Methods for Systems Development in Professional Organisations, Studentlitteratur, Lund, pp. 208-230 (2001)

15. Al-Mashari, M.: Enterprise Resource Planning Systems: A Research Agenda. Industrial Management and Data Systems 102(3), 165-170 (2002)

16. Kumar, K., van Hillegersberg, J.: ERP experiences and evolution. Communications of the ACM 43(4), 23-26 (2000)

17. Möller, C.: ERP II: a conceptual framework for next-generation enterprise systems? Journal of Enterprise Information Management 18(4), 483-497 (2005)

18. Sawyer, S.: Packaged software: Implications of the differences from custom approaches to software development. European Journal of Information Systems 9, 47-58 (2000) 
19. Carmel, E., Becker, S.: A process model for packaged software development. IEEE Transactions on Engineering Management 41(5), 50-61 (1995)

20. Hedman, J., Lind, M.: Is There Only One Systems Development Life Cycle? In: Barry, C., et al. (eds.) Information Systems Development: Challenges in Practice, Theory, and Education, vol. 1, pp. 105-116. Springer, Heidelberg (2009)

21. Grabski, S.V., Leech, S.A.: Complementary controls and ERP implementation success. International Journal of Accounting Information Systems 8(1), 17-39 (2007)

22. Brockmann, C., Gronau, N.: Business Models of ERP System Providers. In: AMCIS 2009 Proceedings. Paper 582 (2009)

23. Johansson, B., Newman, M.: Competitive advantage in the ERP system's value-chain and its influence on future development. Enterprise Information Systems 4(1), 79-93 (2010)

24. Brandt, P., Carlsson, R., Nilsson, A.G.: Välja och Förvalta Standardsystem, Studentlitteratur, Lund (1998)

25. Sumner, M.: Enterprise Resource Planning. Prentice Hall, Upper Saddle River (2004)

26. Parr, A., Shanks, G.: A Model of ERP Project Implementation. Journal of Information Technology 15(4), 289-304 (2000)

27. Papazoglou, M.P.: Service-oriented computing: Concepts, characteristics and directions. In: Fourth International Conference on Web Information Systems Engineering, Rome, Italy (2003)

28. Sun, W., Zhang, K., Chen, S., Zhang, X., Liang, H.: Software as a Service: An integration perspective. In: Krämer, B., Lin, K., Narasimhan, P. (eds.) Service-Oriented Computing ICSIC 2007, Vienna, Austria, September 17-20, pp. 558-569. Springer, Heidelberg (2007)

29. Hoch, F., Kerr M., Griffith A.: Software as a Service: Strategic Backgrounder. Software and Information Industry Association (2001), http://www.siia.net/estore/ pubs / SSB-01.pdf (last accessed April 15, 2011)

30. Mäkilä, T., Järvi, A., Rönkkö, M., Nissilä, J.: How to Define Software-as-a-Service - An Empirical Study of Finnish Saas Providers. In: Tyrväinen, P., Jansen, S., Cusumano, M.A. (eds.) ICSOB 2010. LNBIP, vol. 51, pp. 115-124. Springer, Heidelberg (2010)

31. Turner, M., Budgen, D., Brereton, P.: Turning software into a service. Computer 36(10), 38-44 (2003)

32. Lassila, A.: Taking a service-oriented perspective on software business: How to move from product business to online service business. IADIS International Journal on WWW/Internet 4(1), 70-82 (2006)

33. Xin, M., Levina, N.: Software-as-a-Service model: Elaborating client-side adoption factors. In: Boland, R., Limayem, M., Pentland, B. (eds.) Proceedings of the 29th International Conference on Information Systems, Paris, France, December 14-17 (2008)

34. Wailgum, T.: Impact of SaaS on the enterprise ERP Market. Infoworld (August 2008), http: / /www. infoworld.com/t/applications / impact-saasenterprise-erp-market-090 (last accessed April 15, 2011)

35. Benlian, A., Hess, T., Buxmann, P.: Drivers of SaaS-Adoption - An Empirical Study of Different Application Types. Business \& Information Systems Engineering 1(5), 357-369 (2009)

36. Kaplan, J.: Software-as-a-Service Myths. BusinessWeek Online (April 17, 2006)

37. Bezemer, C.P., Zaidman, A.: Multi-tenant SaaS Applications: Maintenance Dream or Nightmare? In: Proceedings of the 4th International Joint ERCIM/IWPSE Symposium on Software Evolution (IWPSE-EVOL). ACM (2010) 
38. Kwok, T., Mohindra, A.: Resource Calculations with Constraints, and Placement of Tenants and Instances for Multi-tenant SaaS Applications. In: Bouguettaya, A., Krueger, I., Margaria, T. (eds.) ICSOC 2008. LNCS, vol. 5364, pp. 633-648. Springer, Heidelberg (2008)

39. Demirkan, H., Cheng, H.K., Bandyopadhyay, S.: Coordination Strategies in anSaaS Supply Chain. Journal of Management Information Systems 26(4), 119-143 (2010)

40. Stuckenberg, S., Heinzl, A.: The Impact of the Software-as-a-Service Concept on the Underlying Software and Service Development Processes. In: PACIS 2010 Proceedings. Paper 125 (2010)

41. Lillis, A.M., Mundy, J.: Cross-sectional field studies in management accounting research—closing the gaps between surveys and case studies. Journal of Management Accounting Research 17, 119-141 (2005)

42. Eisenhardt, K.M.: Building theories from case study research. Academy of Management Review 14(4), 532-550 (1989)

43. Juell-Skielse, G.: Adoption of Extended ERP Among Small and Medium Sized Companies in Kista Science City. In: Proceedings of the 3rd International Conference on Enterprise Systems and Accounting (ICESAcc 2006), Santorini Island, Greece, June 26-27 (2006)

44. Olhager, J., Selldin, E.: Enterprise resource planning survey of Swedish manufacturing firms. European Journal of Operational Research 146, 365-373 (2003)

45. Wikström, S., Norman, R.: Knowledge and value: a new perspective on corporate transformation. Routledge, London (1994)

46. Utterback, J.: Mastering the dynamics of innovation. Harvard Business School Press, Cambridge (1994)

47. Guba, E.G., Lincoln, Y.S.: Effective Evaluation: Improving the Usefulness of Evaluation Results Through Responsive and Naturalistic Approaches. Jossy-Bass, San Francisco (1981)

48. Bennett, K., Layzell, P.J., Budgen, D., Brereton, P., Macaulay, L., Munro, M.: Servicebased software: The future for flexible software. In: Proceedings of the Asia-Pacific Software Engineering Conference, Singapore, December 5-8, pp. 214-222. IEEE CS Press (2000)

49. Dörner, C., Draxler, S., Pipek, V., Wulf, V.: End Users at the Bazaar: Designing NextGeneration Enterprise Resource Planning Systems. IEEE Software 26(5), 45-51 (2009)

50. Demirkan, H., Chen, H.K.: The risk and information sharing of application services supply chain. European Journal of Operational Research 187(3), 765-784 (2008)

51. Hofmann, P.: ERP is dead, Long live ERP. Internet Computing. IEEE Publication 12(4), 84-88 (2008)

52. Jacobs, D.: Enterprise Software as Service. Queue, 36-42 (July/August 2005)

53. Rettig, C.: The Trouble with Enterprise Software. MIT Sloan Management Review 49(1), 21-27 (2007)

54. Rochwerger, B., Breitgand, D., Levy, E., Galis, A., Nagin, K.: The reservoir model and architecture for open federated cloud computing. IBM Systems Journal (October 2008)

55. Saeed, M., Jaffar-Ur-Rehman, M.: Enhancement of software engineering by shifting from software product to software service. In: Khan, W., Ahmed, F. (eds.) First International Conference on Information and Communication Technologies (ICICT 2005), Karachi, Pakistan, August 27-28, pp. 302-308 (2005)

56. Sharif, A.M.: It's written in the cloud: the hype and promise of cloud computing. Journal of Enterprise Information Management 23(2), 131-134 (2010) 
57. Susarla, A., Barua, A., Whinston, A.: A transaction cost perspective of the "software as a service" business model. Journal of Management Information Systems 26(2), 205-240 (2009)

58. Torbacki, W.: SaaS-direction of technology development in ERP/MRP systems. International Scientific Journal 32(1), 57-60 (2008)

59. Armbrust, M., Fox, A., Griffith, R., Joseph, A.D., Katz, R., Konwinski, A., Lee, G., Patterson, D., Rabkin, A., Stoica, I., Zaharia, M.: A view of cloud computing. Communications of the ACM 53(4), 50-58 (2010)

\section{Appendix}

\begin{tabular}{|c|c|c|c|c|c|c|}
\hline \multicolumn{4}{|c|}{ User Opportunities } & \multicolumn{3}{|c|}{ User Challenges } \\
\hline Impl. & References & \multicolumn{2}{|c|}{ Cases } & Impl. & References & Cases \\
\hline UO01 & {$[7,8,39,32,1,58]$} & \multicolumn{2}{|c|}{$\mathrm{D}, \mathrm{F}$} & UC01 & {$[21]$} & \\
\hline $\mathrm{UO} 02$ & {$[8,9,53,57,1,58]$} & \multicolumn{2}{|c|}{$\mathrm{F}, \mathrm{G}, \mathrm{H}, \mathrm{I}$} & UC02 & [21] & \\
\hline $\mathrm{UO03}$ & {$[8,52,55,58]$} & \multicolumn{2}{|c|}{$\mathrm{A}, \mathrm{B}, \mathrm{C}, \mathrm{D}, \mathrm{E}, \mathrm{G}$} & UC03 & [21] & \\
\hline UO04 & {$[25]$} & \multicolumn{2}{|c|}{ (2) } & UC04 & [21] & \\
\hline UO05 & [25] & & UC05 & [13] & \\
\hline UO06 & [25] & \multicolumn{2}{|c|}{$\mathrm{A}, \mathrm{C}$} & UC06 & [21] & \\
\hline UO07 & & \multicolumn{2}{|c|}{$\mathrm{D}$} & UC07 & [21] & \\
\hline UO08 & [25] & \multicolumn{2}{|l|}{$\mathrm{A}$} & UC08 & & $\mathrm{H}$ \\
\hline UO09 & [1] & \multicolumn{2}{|c|}{$\mathrm{D}, \mathrm{I}$} & UC09 & {$[35,10,55,1,13]$} & $\mathrm{D}, \mathrm{G}, \mathrm{H}, \mathrm{I}$ \\
\hline UO10 & {$[8,55]$} & & & UC10 & {$[1,13]$} & $\mathrm{C}, \mathrm{I}$ \\
\hline UO11 & {$[35,1,58]$} & \multicolumn{2}{|l|}{$\mathrm{C}$} & UC11 & {$[35,1,13]$} & $\mathrm{H}$ \\
\hline UO12 & [1] & \multicolumn{2}{|c|}{ C, D, F, G, H, I } & $\mathrm{UC} 12$ & {$[35,1,58,13]$} & $\mathrm{G}, \mathrm{H}, \mathrm{I}$ \\
\hline UO13 & {$[8,55,58]$} & & $\mathrm{UC13}$ & & $\mathrm{C}$ \\
\hline UO14 & {$[8,32,1,58]$} & & UC14 & [13] & $\mathrm{C}, \mathrm{I}$ \\
\hline UO15 & {$[35,32,1]$} & \multicolumn{2}{|c|}{ B } & UC15 & [13] & $\begin{array}{l}\mathrm{C}, \mathrm{I} \\
\mathrm{C}\end{array}$ \\
\hline UO16 & {$[1,58]$} & \multicolumn{2}{|l|}{$\mathrm{H}$} & UC16 & {$[21,24]$} & $\mathrm{C}$ \\
\hline UO17 & [25] & & UC17 & [21] & \\
\hline UO18 & [25] & & & UC18 & [21] & \\
\hline UO19 & [25] & \multicolumn{2}{|c|}{$\mathrm{A}, \mathrm{D}$} & UC19 & & $\mathrm{C}$ \\
\hline $\mathrm{UO} 20$ & [25] & $\mathrm{A}$ & & & & \\
\hline $\mathrm{UO} 21$ & [25] & $\mathrm{A}$ & & & & \\
\hline $\mathrm{UO} 22$ & [25] & G & & & & \\
\hline $\mathrm{UO} 23$ & & $\mathrm{C}$ & & & & \\
\hline UO24 & & G & & & & \\
\hline $\mathrm{UO} 25$ & & $\mathrm{D}$ & & & & \\
\hline UO26 & {$[8,35,32,1]$} & & $\mathrm{H}, \mathrm{I}$ & & & \\
\hline Suppli & Opportunities & & & Suppl & ier Challenges & \\
\hline Impl. & References & & Cases & Impl. & References & Cases \\
\hline SO01 & {$[32,1]$} & & $\mathrm{D}, \mathrm{I}$ & $\mathrm{SC} 01$ & {$[1,36,32,58,9,12$} & \\
\hline SO02 & [12] & & $\mathrm{D}$ & $\mathrm{SC} 02$ & {$[1,32]$} & $I$ \\
\hline SO03 & {$[18,19,20]$} & & & $\mathrm{SC} 03$ & {$[20]$} & \\
\hline
\end{tabular}




\begin{tabular}{|c|c|c|c|c|c|}
\hline SO04 & {$[32,56,1]$} & $\mathrm{A}, \mathrm{G}$ & SC04 & [12] & \\
\hline $\mathrm{SO} 05$ & & A & $\mathrm{SC} 05$ & {$[1,7,52,32,13,9]$} & $\mathrm{H}$ \\
\hline SO06 & {$[12,9,55]$} & $\mathrm{A}, \mathrm{B}, \mathrm{D}, \mathrm{I}$ & SC06 & & $\mathrm{C}$ \\
\hline $\mathrm{SO} 07$ & [1] & $\mathrm{A}, \mathrm{D}$ & $\mathrm{SC} 07$ & {$[1,48,32]$} & \\
\hline SO08 & & $\mathrm{A}, \mathrm{C}$ & SC08 & & $\mathrm{C}$ \\
\hline SO09 & & $\mathrm{E}$ & SC09 & & $\mathrm{C}$ \\
\hline SO10 & & A & SC10 & {$[1,39,54,40,13,32]$} & $\mathrm{A}$ \\
\hline SO11 & [55] & & $\mathrm{SC} 11$ & [49] & \\
\hline SO12 & {$[18,19,20,1,37,52]$} & A & $\mathrm{SC} 12$ & {$[40,9]$} & \\
\hline SO13 & {$[35,37,8,51,52,32,54,1]$} & $\mathrm{B}$ & SC13 & [20] & \\
\hline $\mathrm{SO} 14$ & {$[48,8,54]$} & & $\mathrm{SC} 14$ & [53] & $\mathrm{I}$ \\
\hline SO15 & {$[19,20,18]$} & & SC15 & {$[13,37]$} & \\
\hline SO16 & [32] & & SC16 & {$[52,27,37]$} & \\
\hline SO17 & {$[19,20,18]$} & & SC17 & $\begin{array}{l}{[1,7,12,32,27,37,} \\
52]\end{array}$ & $\mathrm{C}$ \\
\hline SO18 & [8] & $\mathrm{I}$ & SC18 & {$[59,50]$} & \\
\hline \multirow[t]{2}{*}{ SO19 } & [54] & & SC19 & [20] & \\
\hline & & & $\mathrm{SC} 20$ & & A, C \\
\hline
\end{tabular}

